\title{
The Displacement Impacts of Wind Power Electricity Generation: Costly Lessons from Ontario
}

\author{
Pejman Bahramian \\ Department of Economics, Queen's University, Kingston, Canada \\ E-mail: bahramian@econ.queensu.ca \\ Glenn P. Jenkins \\ Department of Economics, Queen's University, Kingston, Canada and \\ Eastern Mediterranean University, North Cyprus \\ E-mail: jenkins@econ.queensu.ca \\ Frank Milne \\ Department of Economics, Queen's University, Kingston, Canada \\ E-mail: milnef@econ.queensu.ca
}

\section{Development Discussion Paper: 2020-22}

\begin{abstract}
The displacement impacts of wind power generation on other generation technologies are estimated for Ontario. In addition, their annual financial benefits, costs, and international stakeholder impacts are measured. For every $100 \mathrm{MWh}$ generated, almost $53 \mathrm{MWh}$ of gas output and $23 \mathrm{MWh}$ of hydro output is displaced, and $19 \mathrm{MWh}$ of power is exported. Ontario loses 826.42 million USD annually from having wind power generation in the system, while the US gains 7.50 million USD through electricity exported from Ontario. Wind power generation has produced an estimated 108.98 million USD in reducing CO2 emissions in the US and Ontario through displacing thermal generation. Comparing the environmental benefits with the net cost to consumers shows the promotion of wind power generation to be largely a waste of Ontario's resources.
\end{abstract}

Keywords: wind power, thermal displacement, $\mathrm{CO} 2$ emissions, stakeholder analysis

JEL Classification: O10, Q48

Revised Version Published as: Bahramian, P; Jenkins, P.,G; Milne, F. The displacement impacts of wind power electricity generation: Costly lessons from Ontario. Energy Policy Volume152 https://doi.org/10.1016/j.enpol.2021.112211. 
Acknowledgments: This study has benefited greatly from discussions with Peter Kascor, Arnold C. Harberger, and members of the public economics seminar at the Middle East Technical University, in North Cyprus. Financial support for this research through a Mitacs AcceleratePDF Fellowship [IT13680] is greatly appreciated. 


\section{Introduction}

In recent years, renewable energy sources (RESs) utilizing wind and solar energy have become a practical alternative for reducing the dependence on fossil fuels for electricity generation (Van Kooten 2016). Such plants serve to reduce the fuel costs of the utility and yield further environmental benefits (Ma et al. 2014). Concerns about climate change and energy security have stimulated renewable electricity generation deployment by electric utilities around the world. By displacing output from other power sources, such as coal and gas-fired plants, RESs reduce total greenhouse gas (GHG) emissions and air pollution (Benitez et al. 2008; Kriegler 2011).

In 2004 the Government of Ontario introduced the first of several programs designed to encourage private investment in renewable energy. The Province later established its Green Energy and Green Economy Act (2009), commonly referred to as the Green Energy Act (GEA), in response to the global call to reduce GHG emissions (Oji and Weber 2017). Most of the growth in renewable project development occurred in Ontario within the period 2009-2016. The Province's feed-in tariff program was eventually phased out in 2018. By December 2018, the Province had installed, through support from various incentive and guarantee programs, a total of 5,076 MW of wind generation capacity (IESO 2018). While the program was successful in that it brought forth investments in renewable electricity generation, particularly wind power, the question remains as to the financial feasibility of these investments from the perspective of the Province of Ontario.

This study aims to examine the displacement effect of wind generation on the other electricity generation types within the Province of Ontario for the period 2015-2018. More precisely, we propose to model the changes in the amount of gas-fueled, hydro, and nuclear electricity generated as a result of the output of electricity produced by the wind farms in Ontario. This will be done at the aggregate system level (i.e. output by fuel type), rather than at the individual plant level. Net exports will also be modeled in the same way. This displacement will be quantified in terms of the quantities of energy that no longer need to be generated by these alternative generation technologies. 
Using these results, an estimate can be made of the annual value of the fuel saved along with the reduction in the quantity and estimated social value of the GHG that would otherwise have been created. The additional export of power from Ontario to neighboring jurisdictions may arise because of the additional demand for electricity in these export markets. It might also arise if at the time that electricity is being generated by the wind farms it is not financially worthwhile to displace further thermal generation in Ontario while the export price offered by Ontario is attractive to other jurisdictions relative to the cost of own generation. In both of these situations the result will be a displacement of the operation of other generation technologies in these export jurisdictions. As long as a positive export price can be obtained for the power, it is financially more attractive to export the power than to shut down Ontario's wind generators. It is important, however, to highlight that electricity customers in Ontario are being forced to pay more to the operators of the wind farms for this exported energy than is received from export sales (Yauch and Mitchnick 2016).

In some cases, when the supply of electricity in Ontario is greater than the demand for electricity and there is no ready export demand for electricity, it may be offered to importers at negative prices. Ontario is not alone in occasionally facing the problem of the negative export price for electricity: Germany, too, also faces the same issue. Germany has frequently been forced to pay other countries to take its surplus electricity because its power network cannot cope with the surge in generation by renewables. The non-economic storage possibilities of large amounts of energy and unit commitment, in combination with the very limited flexibility of demand, lead to the occurrence of bids below variable costs, and even negative ones (Nicolosi 2010).

In the stakeholder analysis, the benefits and costs realized in power-importing jurisdictions through the import of additional electricity from Ontario will be estimated. Note that the financial cost to the electricity system of the electricity production by the wind farms estimated here is an approximate measure, as it includes only the payments from the Independent Electricity System Operator (IESO) to the owners of the wind farms. This estimation, however, can be further adjusted by including government subsidies, taxes paid by the wind farm owners, and the additional capital costs required to stabilize the effects of intermittency. As the other costs are often related to the particulars of an individual project, we set them aside for this macro-based level analysis. 
Due to the intermittent nature of solar and wind power, electricity generated by these sources of energy cannot be dispatched in the same manner as hydro or thermal generation. Hence, they are not continuously available to meet the demand for electricity. Increasing the deployment of such renewable electricity generation also brings power-balancing challenges to avoid frequency deviations in the electricity system (Van Kooten 2016). Any significant implementation of renewable generation technologies within an electricity industry will influence the physical dispatch of the existing generation plants and the commercial outcomes for participants. Plants with dispatchable generation must be ready to back up the generation of wind or solar if there is a sudden drop in their production (Currie et al. 2006). To ensure the target level of reliability of the system's electricity service, RESs must be combined with the other sources of electricity generation in ways that are affordable, reliable, flexible, clean, safe, and efficient (Graf and Marcantonini 2017).

In the case of Ontario investments are being made in gas powered generation plants to allow the Province to reduce its dependency on nuclear generation and to eliminate in 2015 generation of electricity with coal. The expansion in the capacity of gas powered generation is also complementary to the investments in renewable sources of energy such as wind and solar generation. The capacity in electricity generation with gas is necessary in order to meet any deficit in the supply of electricity during periods when the renewable sources of generation are not operative. The role of the non-hydro renewable supplies is to reduce the amount of fuel that would otherwise have to be used to generate electricity by the gas fired plants, plus to increase the amount generated in Ontario so that a greater supply of exports of electricity can be made. Hence, investments in renewable generation capacity and investments in generation capacity using natural gas are complementary. The capacity in gas generation can always be used to meet the demand for electricity when the generation capacity by the renewables is not able to function. However, when the renewable generation capacity is operating the electricity it generates will in many circumstances serve to reduce the generation by gas plants.

Merit order dispatching is a way of ranking available sources of electricity based on ascending order of marginal cost (or variable operating cost), together with the amount of electricity that will be generated. Plants with the lowest marginal costs should be dispatched first to meet demand, 
while plants with the highest marginal costs should be dispatched last (Ummels et al. 2006; Delarue, Luickx and D'haeseleer 2009; Göransson and Johnsson 2009; Green and Vasilakos 2010; Bell et al. 2017). Dispatching generation in this way minimizes the total cost of electricity generation. Given that electricity generated by wind power has approximately a zero marginal cost if available, it will be used first and will displace output from other dispatchable generation plants that have higher marginal costs. As nuclear generation is technically difficult to displace, wind generation is likely to cause a reduction in hydro/gas/oil/solar/biofuel generation. For an interconnected utility, it may bring about an increase in net exports. Thus, policymakers need to know how the power plants across their generation system will be affected in the presence of wind power. In this way, decision-makers can prepare an optimal energy paradigm for their jurisdiction to achieve environmentally sound and sustainable development.

The recent attention paid to the consequences of high wind penetration in utility operations provides an extensive body of literature examining the possible effect of wind generation on the supply of other generators. This impact is quantified in various places around the world, through descriptive (Cutler et al. 2011), simulation (Sensfuß, Ragwitz and Genoese 2007; Lamont 2008), and empirical (Nicholson and Porter 2010; Woo et al. 2011) studies. However, no research has yet been undertaken in the context of the Province of Ontario.

Using the developed methodology, estimates will be made of the displacement effect of each type of Ontario's existing power suppliers. To our knowledge, this will be the first study implemented in Canada that investigates the output displacement using the substantial historical operating database available from IESO for Ontario. It includes all the necessary information regarding each electricity generation type within Ontario and simultaneously hourly market prices for electricity. The findings of this study are intended to assist electricity system planners in Ontario and other jurisdictions to design efficient policies to address their climate change action plans.

\subsection{Ontario Energy Supply Paradigm}

To quantify this generation displacement by the wind farms, we need to understand how Ontario's power system has responded historically to the infusion of electricity generation from 
wind farms. Ontario's electricity grid has a diverse supply mix, featuring nuclear baseload generators that provide energy with a high load factor, intermittent generators that generate when they are able (primarily wind and solar), and flexible generators that can change their output quickly (primarily single-cycle natural gas generation and hydropower generation). Because renewables have very low marginal operating costs, they can offer bids to enter the market at low offer prices. By entering the spot market ("price pool") at the low end, they displace generators who bid in at higher prices, typically gas-fired plants.

The Province has experienced a surplus of off-peak electricity supply in recent years. During high-demand periods, wind power displaces relatively expensive gas generation. However, during low-demand periods, because the wind is given priority in electricity generation within the system, it may also displace low-cost hydro generation. Surplus electricity may also be sold to neighboring jurisdictions if there are willing buyers.

In 2018, more than 93 percent of electricity generated in Ontario came from green resources (nuclear, hydro, wind, and solar). Renewables—wind, solar, and biofuel-now account for 14 percent of installed generating capacity (MW) and almost 8 percent of total output (TWh) (IESO 2018). Table 1 shows electricity generation by fuel type during 2018 for the Province of Ontario based on the annual report provided by IESO. As shown in Table 1, nuclear plants were responsible for most of the power generation -61.08 percent of output-followed by hydro at 24.53 percent. Wind and gas/oil accounted for 7.22 percent and 6.48 percent of output, respectively. Biofuel and solar combined accounted for less than 1 percent of output. Since biofuel and solar play such a minor role, they will be omitted from the output displacement estimation.

Another important issue is that the variability of the wind and the inability of the wind turbines to produce their maximum nameplate capacity leads them to have a much lower capacity factor than thermal power plants. The study by Hoskins (2015) on Europe indicated that the capacity factor of onshore and offshore wind power averaged 21.2 percent and 30.0 percent, respectively, in 2013. The average capacity factor for wind turbines in the EU is reported to be 22 percent compared with 33 percent for the US and only 17 percent for China, based on 2012 data (LacalArántegui 2013). 


\begin{tabular}{lcc}
\hline Type & Total installed capacity (\%) & Percentage of total yearly output (\%) \\
\hline Nuclear & 35.23 & 61.08 \\
Gas & 22.97 & 6.48 \\
Hydro & 27.83 & 24.53 \\
Wind & 12.15 & 7.22 \\
Solar & 0.80 & 0.39 \\
Biofuel & 1.03 & 0.29 \\
\hline
\end{tabular}

Source: IESO Reliability Outlook (2018)

\section{Proposed Methodology and Related Literature}

There are various ways to estimate output displacement. Most of the studies in this field are aimed at measuring the effect of wind generation output on electricity prices, and, as previously mentioned, the effect can be quantified from descriptive, simulation, and empirical perspectives. To date, many of the studies concerning the impact of output displacement on electricity prices have employed a simulation framework. For example, Weigt (2009) analyzed the extent to which wind energy can replace fossil capacities within Germany. He modeled the German market with and without wind input to estimate the net savings in fossil fuels in the observation period (20062008). The market model was designed to minimize costs, including unit commitment and startup costs. The market was assumed to be perfectly competitive and characterized by a set of plants with constant marginal costs. Demand was taken as being externally given and formed the total output constraint. Each plant was subject to capacity constraints, with upper and lower bounds on generation. Start-up times were also built into the model. Pumped storage plants were included to allow for more flexible dispatch. The model was solved for a set of hours covering the entire observation period. However, the model did not consider the import/export of electricity to neighboring jurisdictions. In another study, Green, Vasilakos and Kensington (2011) examined the effect of wind energy on optimal generation mixes in the context of the British electricity industry. Their findings showed that the effect of wind on the price will be neutralized in the long run by the rise in a more expensive flexible generation. This implies that the behavior of the other power plants counteracts the reduction in price in the short term.

Empirical studies assessing the impact of wind generation on the price are also worthy of mention. Among them, Woo et al. (2011), using regression analysis, examined the impact of wind 
generation on balancing market prices in the Electric Reliability Council of Texas (ERCOT) market in Texas, US. Their results indicated that with $1 \mathrm{MWh}$ rise in wind generation, the spot price falls by between $1.30 \mathrm{c} / \mathrm{MWh}$ and $4.40 \mathrm{c} / \mathrm{MWh}$.

Another strand of research has examined the effect of wind generation on GHG emissions. The study by Amor et al. (2014) looked at GHG emission reductions due to wind energy in Ontario. They used three relatively simple approaches to look at output displacement. The "average approach" sidesteps the output displacement question and uses an average GHG emission rate ( $\left.\mathrm{kg} \mathrm{CO}_{2} / \mathrm{MWh}\right)$ across all types of generation within Ontario. The "marginal approach" attempts to identify the marginal generating unit being used in each hour of the day. The type of generation showing the greatest variation in output between a given hour and the preceding one is deemed to be the marginal unit for that hour. Once marginal units are identified on an hourly basis, the specific GHG emission rates are used to quantify the emissions avoided because of wind generation. The "hybrid approach" recognizes that almost all power plants change their production on an hourly basis. This suggests that changes because of wind production have an impact on a variety of power plants. For this approach, the individual contribution of each generation type to the variation of the total hourly electricity production between one hour $(t)$ and the preceding one $(t-1)$ was estimated. This was used as the basis to calculate a weighted GHG emission impact of wind generation. Kaffine, McBee and Lieskovsky (2013), using hourly data on wind generation and emissions from plants in ERCOT (Texas), empirically examined the impact of wind generation on the reduction of GHG emissions. Their results revealed that substantial variation exists in emission reductions due to the differences in the generation mix. In another study, Cullen (2013) quantified the environmental benefits of wind-generated electricity in Texas using the randomness inherent in wind power availability. His findings illustrated that only for high estimates of the social costs of pollution does the value of emissions offset by wind power exceed the cost of renewable energy subsidies.

In their study on the displacement effect of wind farms in Australia, Forrest and MacGill (2013) undertook an econometric analysis of historical hourly demand and electricity generation across the system to estimate the impact of wind generation on the output of other types of generation. 
They suggested that there is a market impact on the spot price in the presence of wind generation, while wind output leads to an offsetting of high operating cost gas generation.

Our proposed analysis will build on the work of Forrest and MacGill (2013) to estimate the actual historical displacement effects of the wind farms within the Province of Ontario. Following their approach, we can estimate output displacement based on the four estimation equations, designated as:

$$
z_{i t}=\alpha_{0}+\alpha_{1} w_{t}+\sum_{i=1}^{3} \beta_{i} a c_{i t}++\alpha_{2} o d_{t}+\alpha_{3} e d_{t}+\varepsilon_{t}
$$

where $z_{i t}$ denotes nuclear, hydro, gas, and net export outputs, at time $t ; w_{t}$ is the wind output, at time $t ; a c_{i t}$ stands for the generating capacity available for dispatch, by fuel type, at time $t ; o d_{t}$ signifies the Ontario demand for power at time $t$; and $e d_{t}$ is the external demand for power received by IESO at time $t$ from the other jurisdictions.

It should be stressed that although our approach to measuring the displacement effects by wind generation of other generation technologies is based on the study by Forrest and MacGill (2013), the framework is similar to those of Cullen (2013), Kaffine, McBee and Lieskovsky (2013), and Novan (2015), for the US, who were mostly concerned with the environmental benefits of wind generation.

\section{Data and Empirical Findings}

For the econometric work, we use the available daily data for the period 2015-2018 from the IESO's Data Directory. ${ }^{1}$ The reasons for using daily data relate to the average daily flow constraints faced by hydro plants. In a 24-hour period, reservoirs can store water "off-peak," then release it "on-peak" for generation. But there are limits to the amount of water that can be stored across days.

To maintain average daily flow requirements in Ontario, stored water must usually be released on the same day through the turbines. Hence, the hydro generation that is displaced by the wind farms will result in either an increase in water storage for generation later in the day or spilled

\footnotetext{
${ }^{1}$ Available at IESO Data Directory (http://www.ieso.ca/en/power-data/data-directory).
} 
water. When the water is released for generation, the electricity produced will result in a displacement of the generating plants using gas or will cause additional electricity to be exported.

\begin{tabular}{cc}
\hline & Abbreviations \\
\hline OW & Output generated by wind (MWh) \\
OG & Output generated by gas ((MWh) \\
OH & Output generated by hydro (MWh) \\
ON & Output generated by nuclear (MWh) \\
ACG & Available capacity of gas (MW) \\
ACH & Available capacity of hydro (MW) \\
ACN & Available capacity of nuclear (MW) \\
OD & Ontario demand (MWh) \\
ED & External Demand (MWh) \\
NX & Net exports $(\mathrm{MWh})$ \\
\hline
\end{tabular}

The data for the net exports consist of the flows over the intertie zones: Manitoba (MBSI), Minnesota (MNSI), Michigan (MISI), New York (NYSI), and Quebec. Ontario currently has interconnections with these five neighbors. Being a part of an interconnected grid means that Ontario can export and import across all interties. From the perspective of IESO, the total market demand includes the demand by Ontario consumers as well as the external demand from other jurisdictions determined by the contracts, they have with IESO. Thus, the daily values for the external demand are derived by subtracting the Ontario consumers demand for the day from the corresponding total market demand as reported by IESO.

Table 2 reports the displacement behavior of wind electricity power as quantified by the output models for gas, hydro and nuclear generation and net exports. ${ }^{2}$ As can be seen from Table 2, daily wind output $(\mathrm{OW})$ reflects the actual wind energy generated by the wind farms in Ontario's power system. The impact of wind on gas power generation is strongly significant, with an approximate magnitude of -0.53 . This shows that wind generation of electricity has the capability to displace power generation using gas-fired stations. This result confirms the conclusion of the simulation studies (Delarue, Luickx and D'haeseleer 2009; Green and Vasilakos 2010) and the empirical

\footnotetext{
${ }^{2}$ We also estimate a model that applies a constraint imposing the equality of supply and demand of electricity in the system. Our estimation shows that our findings in Table 2 are robust in the presence of this constraint. We did not report the results of this examination formally, although they are available from the authors on request.
} 
study by Forrest and MacGill (2013), which suggested that wind has a significant effect on generators that are positioned at the upper end of the supply curve.

Table 2. OUTPUT DISPLACEMENT MODELS

\begin{tabular}{ccccc}
\hline & OG & OH & NX & ON \\
\hline OW & $-0.534^{* * *}$ & $-0.233^{* * *}$ & $0.194^{* * * *}$ & 0.015 \\
& $(0.028)$ & $(0.028)$ & $(0.023)$ & $(0.012)$ \\
ACG & 0.025 & $-0.080^{* *}$ & $-0.072^{* * * *}$ & $-0.035^{* * * *}$ \\
& $(0.032)$ & $(0.046)$ & $(0.025)$ & $(0.012)$ \\
ACN & $-0.435^{* * * *}$ & $-0.192^{* *}$ & $0.273^{* * * *}$ & $0.919^{* * *}$ \\
& $(0.037)$ & $(0.067)$ & $(0.039)$ & $(0.015)$ \\
ACH & $-0.436^{* * *}$ & $0.546^{* * *}$ & $0.091^{*}$ & -0.023 \\
& $(0.044)$ & $(0.076)$ & $(0.055)$ & $(0.019)$ \\
OD & $0.562^{* * * *}$ & $0.153^{* * *}$ & $-0.211^{* * *}$ & $0.068^{* * *}$ \\
& $(0.020)$ & $(0.022)$ & $(0.021)$ & $(0.011)$ \\
ED & $0.461^{* * *}$ & $0.240^{* * *}$ & $0.814^{* * *}$ & $0.051^{*}$ \\
& $(0.065)$ & $(0.074)$ & $(0.051)$ & $(0.028)$ \\
\hline
\end{tabular}

Notes: Robust standard errors are shown in parentheses. ${ }^{*} p<0.05,{ }^{* *} p<0.01,{ }^{* * *} p<0.001$.

For the case of hydro output $(\mathrm{OH})$, the size of the coefficient reflecting the degree of its displacement is smaller than the coefficient that measures the size of the displacing of OG. The significant coefficient of -0.233 indicates that for every $100 \mathrm{MWh}$ of wind output, $23 \mathrm{MWh}$ of hydro output is displaced. Nuclear is pure baseload, with very limited flexibility. The wind has no impact on its daily output. Its corresponding coefficient is close to zero, and not statistically significant. This issue highlights the fact that in systems with thermal generation dominated by inflexible plants such as nuclear, it may not be possible to absorb all the wind power that is produced primarily in the off-peak periods. In such a system, if there is some storage capacity available in the existing hydro plants, this will increase the capability of the system to incorporate wind power (Strbac et al. 2007). This highlights the difficulty of integrating wind generation within the Ontario electricity system. In the short run, nuclear generation output cannot be lowered sufficiently when demand is low. On a seasonal basis, the Bruce Nuclear Power plant is the exception - it has recently been using the total capacity of only 2,400 MW, out of a nameplate capacity of $6,300 \mathrm{MW}$. The poor alignment of wind production with demand combined with inflexible nuclear generation and a lack of storage makes integrating wind generation into the grid difficult and costly (Ontario Society of Professional Engineers (OSPE), 2012). The effect of wind 
output (OW) on net exports (NX) is statistically significant, with a coefficient of 0.194 . For every $100 \mathrm{MWh}$ of additional wind output, 19.4 MWh is exported, mainly to New York and Michigan.

The primary objective of the system operator is to meet demand without interruption. With no real ability to store electricity, the output must be adjusted to follow demand. For this reason, net exports (NX) is negatively correlated with Ontario demand (OD). As demand goes up, there is less power left over within the system for export. However, increases in the external demand (ED) for power has a positive and significant impact on net exports (NX).

The coefficients for available capacity (ACG-ACN-ACH) all have the expected signs. The coefficients on available hydro capacity $(\mathrm{ACH})$ have various signs over the four estimated models. When the nuclear and gas outputs are both assigned as a dependent variable, hydro capacity availability has a significant negative impact, while in the case of net export, it has a significant positive effect. The effects of the average available capacity of gas (ACG) are negative for nuclear and hydro. This means that when the nuclear or hydro plants are down for maintenance, more gas capacity is made available to meet the demand.

Available capacity (ACG-ACH-ACN) also reflects the physical reality of Ontario's system. The output from a given type of generation is positively related to its available capacity. For example, gas output drops when reactors or hydro plants are brought on line. Conversely, gas output jumps when reactors or hydro plants are shut down. In the same manner, nuclear output (ON) increases strongly when reactors are brought on line. Nuclear output drops off when reactors are shut down. Output from a given type of generation is negatively correlated with the availability of substitute power generation technologies.

In sum, our estimation shows that more than half of wind generation (approximately 53 percent) leads to gas displacement. Approximately 19 percent of wind output leads to incremental exports of electricity. The remaining wind generation (approximately 23 percent) leads to hydro displacement, although the hydro is a low-cost producer of electricity, is a renewable resource, and produces no GHGs. It should be noted that almost 96 percent of the daily wind output is accounted for $(-0.534-0.233-0.194=-0.961)$. The penetration of intermittent renewables to the electricity 
supply necessitates extra ramping that gas plants must conduct to balance the wind generation due to the fluctuations in the amounts of electricity generated by wind farms. In the case of Ontario, our estimates indicate that wind farms necessitate additional gas generation for this purpose, amounting to approximately 4 percent of the electricity generated by wind. (For details, see Doherty and O’Malley (2003); Holttinen (2004); and Strbac et al. (2007)).

\subsection{Monetary value of the substitution of wind farm electricity in Ontario and the US}

Wind power generated into the system provides financial benefits for Ontario, through the fuelsaving that stems from the displacement of gas-fired generators and export revenues from the additional electricity sales. The estimated external environmental benefits from the reduction in the social cost of $\mathrm{CO}_{2}$ emissions need to be considered, as the motivation of the Government of Ontario for promoting wind power electricity generation was to reduce GHG emissions. These external environmental benefits arise from the substitution of electricity generated by the wind farms for that of the gas-fired plants in both Canada and its major export market, the US.

The US electric utilities have gained financially from importing additional electricity from Ontario. More imports from Ontario result in less electricity production through natural gas (fuelsaving) in the $\mathrm{US}^{3}$ and, accordingly, less GHG emissions. This section aims to calculate the monetary value of these gains in both Ontario and the US. We further estimate the cost side of these benefits in both regions to draw a conclusion based on the net financial and global impacts.

In the first step, it is important to know that the wind farms in Ontario receive payments based on the estimated capability (CAP $)^{4}$ to generate during any period, rather than the actual output (OW) generated. The estimated CAP is based on the strength of the wind at the wind farm site at a particular point in time. When Ontario has surplus power that cannot be profitably exported then the IESO will instruct the windfarm to not generate. However, IESO will pay the owner of the

\footnotetext{
3 The US is a main partner for exporting electricity for Ontario. Natural gas was the largest source of US electricity generation in 2018 (EIA, 2019). Thus, on the assumption of the same efficiency in producing electricity through natural gas power plants in the US and Canada, the benefits are assumed and measured.

4 IESO defines CAP as the maximum potential output of the unit or facility under current conditions, which includes maximum unit derates and outages for that hour (details are available in Generator Output and Capability Report, IESO).
} 
windfarm, based on the CAP, even though the wind farm does not generate electricity for that period.

The coefficients in Table 2 are obtained based on the actual output values. The average ratio of the OW to the CAP in Ontario is calculated as 84 percent for the period 2015-2018 using IESO data. On average over this four-year period approximately 16 percent of the payments received by the owners of the windfarms were for electricity that was never generated. Thus, the multiplication of the displacement coefficients in Table 2 by this ratio of .84 gives us an estimate of the displacement impacts of windfarms electricity generation as a proportion of the amount of electricity (CAP) that IESO paid for.

Table 3 reports the displacement impact of wind power generation on the natural gas power plants in Ontario and the US, expressed as a proportion of the electricity generated (Column1) and also as a proportion of the wind energy paid for by IESO (column 2). Only about $44 \%$ of the wind electricity paid for by the IESO ends up displacing natural gas generation in Ontario and 16\% displaces natural gas generation in the USA.

The estimated amounts of the gas saved due to the gas power plant displacement in Canada and the USA are presented in column 3, while the amount of GHG emissions reduced due to the lower production of electricity by natural gas is reported in column 4.

Table 3. DISPLACEMENT EFFECT OF WIND POWER GENERATION ON THE NATURAL GAS POWER PLANTS IN ONTARIO AND THE US (2015-2018)

\begin{tabular}{|c|c|c|c|c|}
\hline & $\begin{array}{c}\text { Displacement ratio } \\
\text { (OP) } \\
1\end{array}$ & $\begin{array}{c}\text { Displacement ratio } \\
\text { (CAP) } \\
2\end{array}$ & $\begin{array}{c}\text { Annual gas saved } \\
\text { (million BTU) } \\
3\end{array}$ & $\begin{array}{c}\text { Annual GHG emissions } \\
\text { saved (tonne) } \\
4\end{array}$ \\
\hline Natural gas power plants in Ontario & 0.53 & 0.44 & $39,426,845.20$ & $2,089,622.80$ \\
\hline
\end{tabular}

An estimated 39,426,845.2 million BTU ${ }^{5}$ of natural gas was annually saved through wind power generation in Ontario, while the amount of natural gas saved in the US as a result of the additional

\footnotetext{
${ }^{5}$ With 11,675,844.25 MWh as an average of the estimated capability (CAP) of wind production over the same interval (2015-2018), the value of the displacement of gas generated output is $11,675,844.25 * 0.44=5,137,371.47 \mathrm{MWh}$. Using the average tested heat rates report of the US Energy Information Administration (EIA, Table 8.2.), the average heat rate of gas power plants for the period 2015-2018 is calculated as $7,674,517.1 \mathrm{BTU} / \mathrm{MWh}$. Thus, the value of fuel saved owing to gas displacement is $(7,674,517.1 * 5,137,371.47) / 1,000,000=39,426,845.20$ million BTU.
} 
electricity exports from Ontario was 14,337,034.61 million BTU. ${ }^{6}$ The reduced usage of natural gas generators lowers $\mathrm{CO}_{2}$ emissions in both regions. As can be seen from column 4, annually this amounted to an estimated reduction of 2,089,622.80 tonne of $\mathrm{CO}_{2}$ in Ontario and $759,862.83$ tonne ${ }^{7}$ of $\mathrm{CO}_{2}$ in the US through wind power generated in Ontario.

After calculating the amount of gas saved in both regions, we can now estimate their monetary values. To this end, we need to multiply the values of gas saved in Ontario and the US by their corresponding natural gas prices. The Dawn Hub price is set for Ontario while the Henry Hub price is applied for the US. Using the information provided in Table 4, the monetary value of the fuel-saving in Ontario due to the gas displacement is found to be 117.50 million USD. Similarly, the monetary value of the gas saved in the US due to the export of electricity from Ontario is 38.28 million USD.

Table 4. AVERAGE NATURAL GAS PRICE FOR THE PERIOD 2015-2018

\begin{tabular}{cc}
\hline & Value in USD/million BTU \\
\hline Dawn Hub natural gas price & 2.98 \\
Henry Hub natural gas price & 2.67 \\
\hline
\end{tabular}

Source: Canadian Enerdata Ltd

The monetary value of the carbon reduced using wind output can also be quantified. However, in the first step, we need to know the social cost of carbon emissions/tonne. Unfortunately, there is no commonly accepted estimate of the social cost of carbon. However, following the estimated social cost of carbon for regulatory impact analysis by the US Environmental Protection Agency (EPA), we set the price of $\mathrm{CO}_{2}$ at $38.25 \mathrm{USD} /$ tonne as an average of the carbon price throughout 2015-2018 (EPA Fact Sheet 2013). Using the designated price of carbon, the total value of savings from reduced $\mathrm{GHG}$ emissions in both regions can be measured by multiplying the price of $\mathrm{CO}_{2}$ by the amount of GHG emissions saved (Table 3, column 4). In this manner, the value of the global environmental benefit of gas displacement in Ontario is found to be 79.92 million USD, while for

\footnotetext{
${ }^{6}$ To quantify this value, we follow the same approach as we applied for Ontario. We consider $11,675,844.25 * 0.16=1,868,135.08 \mathrm{MWh}$ as the quantity of electricity no longer generated by natural gas-fired generation plants because of the generation displaced by the increased electricity exports from Ontario. Again, using the average heat rate of gas power plants of 7,674,517.1 BTU/MWh, and with the assumption of the same efficiency in the US and Canada, the value of fuel (gas) saved in the US as a result of the export of electricity from Ontario becomes $(7,674,517.1 * 1,868,135.08) / 1,000,000=14,337,034.61$ million BTU.

7 of carbon reduction. We use the conversion factor of 0.053 for this transformation. The reason is that the $\mathrm{CO}_{2}$ content of gas is set to $117 \mathrm{lbs} / \mathrm{MBTU}$ based on the US EIA report on carbon dioxide emissions coefficients by fuel (2016), and the ratio of the pounds (lbs)/tonne (1,000 kg) is $2,204.62$. Hence, the amount of fuel (gas) saved in million BTU must be multiplied by 0.053 (117/2204.62) to be expressed in tonnes. In this regard, we have the quantity of gas displaced as $39,426,845.20 * 0.053=2,089,622.80$ tonnes. In similar fashion for the US, using the conversion factor of 0.053 , we have $14,337,034.61 * 0.053=759,862.83$ displaced value of gas in tonnes.
} 
the US, this value is 29.06 million USD. In total, the electricity production using the wind in Ontario provides a total of 108.98 million USD in environmental benefits and represents a positive externality to be enjoyed by the world. However, these benefits must be considered in the context of the costs incurred in their achievement.

In Ontario, the net export due to the wind output generation provides revenues for the Province while at the same time, an equal amount can be considered as a cost for the US due to purchasing exported electricity. The quantity of the net export displaced in Ontario is calculated as 1,868,135.08 MWh (see footnote 6). This value must be multiplied by the export price to obtain its monetary value. The export price of electricity is measured based on the sum of flow-weighted intertie prices over the intertie zones ${ }^{8}$ : Manitoba (MBSI), Minnesota (MNSI), Michigan (MISI), New York (NYSI), and Quebec (Kascor 2017). Our calculations indicate that the average export price between 2015-2018 was 16.48 USD/MWh. Hence, the revenue from the additional net exports that arise because of wind farm generation is 30.78 million USD. In sum, the value of the fuel savings and the sales revenue from the additional exports of electricity due to the wind farm production of electricity into the grid has provided an average value of 148.28 million USD in benefits annually to Ontario over the period 2015-2018.

The estimated financial cost to Ontario's electricity system is here based on the power purchase agreement prices made between IESO and the wind farm owners. To this end, we follow the study of Yatchew and Baziliauskas (2011) and use a price of $110 \mathrm{CAD} / \mathrm{MWh}^{9}$.Taking 11,675,844.25 MWh as an average of the estimated capability (CAP) of wind production over the same interval (2015-2018), the cost of production of this amount of electricity using wind

\footnotetext{
8 However, given that the displacement analysis is estimated based on the daily data (not hourly), one question that may arise is that a large part of wind farm generation happens at night when prices tend to be relatively low. Thus, multiplication of the total daily output by an average daily export price may result in an upward bias in the estimated export revenues. To this end, we compare two daily export prices, the simple average of hourly prices obtained from the daily prices, i.e., $y_{d}=\frac{1}{24}\left(\sum_{t=1}^{24}\right.$ export price $\left._{d t}\right)$, and the wind output-weighted average of hourly prices defined as $x_{d}=\frac{\sum_{t=1}^{24}\left(\text { wind output }_{d t} \times \text { export price }_{d t}\right)}{\sum_{t=1}^{24}\left(\text { wind output }_{d t}\right)}$. Then, through the simple linear regression $\left(x_{d}=\beta_{0}+\beta_{1} y_{d}+\varepsilon_{d}\right)$, we examine the relationship between the variables. If two prices are the same $\left(\beta_{0}=0\right.$ and $\left.\beta_{1}=1\right)$, then export revenue - defined as total daily output multiplied by average daily export price - will not be biased and accordingly, a time-of-day adjustment for export revenue is not required. Our estimate shows that the difference between these two prices is very small, while we fail to reject the null of $H_{0}: \beta_{1}=1$. Hence, we conclude that our defined export price is not biased. We have not formally reported the full result in the paper to save space; however, complete details of the findings are available from the authors on request.

${ }^{9}$ The guaranteed price of wind power in Ontario is confidential, and it varies under different procurement methods. However, the rate of 110 $\mathrm{CAD} / \mathrm{MWh}$ employed in this study is in line with the average price paid to the wind energy developers for different initiative programs, as reported in the Annual Report of the Office of the Auditor General of Ontario (2011).
} 
generation depends on the payments from IESO for output generated. After adjusting this price annually for the Canadian inflation rate, average price of $111.87 \mathrm{CAD} / \mathrm{MWh}$ is found for the period 2015-2018. Using the average nominal exchange rate of 1.34 (USD/CAD) for the same period, reported by the Bank for International Settlements (BIS), the contract price becomes 83.48 USD/MWh. Therefore, the average annual cost of production is estimated to be 974.70 million USD (Table 5, row 4).

Comparing the financial benefits obtained to the financial costs incurred indicates a large annual system loss of 826.42 million USD (Table 5, row 5). It is this loss that must be borne by the various stakeholders of the electricity system, primarily the electricity consumers and taxpayers of Ontario.

Considering the annual net financial loss of 826.42 million USD incurred by the IESO of Ontario and the estimated annual global benefit from GHG reduction of 108.98 million USD, the amount of the net global loss from Ontario wind farms is on average 717.44 million USD per year (Table 5, row 12). The only stakeholders who enjoy a net financial gain are potentially the US importers of electricity and their clients. The findings of this section are summarized in Table 5.

Table 5. SUMMARY OF THE ANNUAL MONETARY VALUES OF WIND ELECTRICITY PRODUCTION (2015-2018)

\begin{tabular}{lc}
\hline & Value in million USD \\
\hline Financial value of gas saving in Ontario & 117.50 \\
Export revenue from additional export sales from Ontario & 30.78 \\
Total annual benefits of wind electricity production in Ontario & $\mathbf{1 4 8 . 2 8}$ \\
Financial cost of electricity production by wind in Ontario & 974.70 \\
Annual net financial gain/loss in Ontario & $-\mathbf{8 2 6 . 4 2}$ \\
\hline Financial value of gas saving in the US & 38.28 \\
Payment from the US to Ontario for export (cost of importing electricity) & 30.78 \\
Net financial gain/loss to US utilities & $\mathbf{7 . 5 0}$ \\
\hline Global environmental benefit of gas displacement in Ontario & 79.92 \\
Global environmental benefit of gas displacement in the US & 29.06 \\
Total global environmental benefits (US and Ontario) & $\mathbf{1 0 8 . 9 8}$ \\
Annual net global benefits from Ontario wind farms & $-\mathbf{7 1 7 . 4 4}$ \\
\hline Source: Authors' calculation &
\end{tabular}

Source: Authors' calculation

It should be stressed that the results of this study provide an overall picture for policy analysts and decision-makers based on a single year's performance. Further examination is needed to draw a more nuanced conclusion. To this end, the economic viability of Ontario wind farms can be explored individually using a lifecycle integrated investment appraisal framework. This is very important as the technique enables the researcher to examine the incremental impact of each 
project, that is, how net receipts, net cash flows, and net economic benefits in the presence of the project can be expected to differ from those that would have prevailed in its absence. In this way, the allocation of the costs and benefits across different players (stakeholders) can be determined and, thus, a clear and more precise inference can be drawn.

\section{Conclusion}

This study calculates the displacement impacts of wind power generation on the other generation technologies within the Province of Ontario. To this end, using the daily electricity generation data of IESO for the period 2015-2018, we develop an econometric model to capture the displacement impacts.

We find that for every $100 \mathrm{MWh}$ generated by wind farms in Ontario, almost $53 \mathrm{MWh}$ of gasfired generation and $23 \mathrm{MWh}$ of hydro output is displaced, and $19 \mathrm{MWh}$ of power is exported. Displacing gas generation with wind helps to lower the cost of electricity but replacing hydro with wind power does the opposite. The fact that the displacement of thermal generation is only equal to $53 \%$ of the wind generation, is evidence of the difficulty of integrating wind power into the Ontario electricity system that is dominated by nuclear power generation. It has been a failure of policy to promote wind power investments when the generation system for the foreseeable future is dependent on nuclear base load power. The propensity for wind generated electricity to occur off peak is in conflict with nuclear power generation. This conflict is partially responsible for the fact that the IESO has only been able to accept $84 \%$ of the potential amount of electricity that the windfarms could have generated.

The Ontario Government's policy of subsidizing the production of electricity by wind farms to reduce GHG emissions has been a spectacularly costly experiment with an annual net financial cost of 826.42 million USD and a global environmental benefit of only 108.98 million USD benefits annually. Given that there are a number of other options for reducing GHG emissions that are far more cost-effective to implement (Gillingham and Stock 2018), the wind electricity generation projects in Ontario appear to be a particularly weak instrument for achieving Ontario's commitments for future GHG reductions. 


\section{Conflict of interest statement}

The authors of this paper certify that they have no affiliations with or involvement in any organization or entity with any financial interest or non-financial interest in the subject matter or materials discussed in this manuscript. 


\section{REFERENCES}

Amor, Mourad Ben, Etienne Billette de Villemeur, Marie Pellat, and Pierre-Olivier Pineau. "Influence of Wind Power on Hourly Electricity Prices and Ghg (Greenhouse Gas) Emissions: Evidence That Congestion Matters from Ontario Zonal Data." Energy 66 (2014): 458-69.

Antweiler, Werner. "A two-part feed-in-tariff for intermittent electricity generation." Energy Economics 65 (2017): 458-470.

Bell, William Paul, Phillip Wild, John Foster, and Michael Hewson. "Revitalising the wind power induced merit order effect to reduce wholesale and retail electricity prices in Australia." Energy Economics 67 (2017): 224-241.

Benitez, Liliana E., Pablo C. Benitez, and G. Cornelis Van Kooten. "The economics of wind power with energy storage." Energy Economics 30, no. 4 (2008): 1973-1989.

Cullen, Joseph. "Measuring the Environmental Benefits of Wind-Generated Electricity." American Economic Journal: Economic Policy 5, no. 4 (2013): 107-33.

Currie, RAF, GW Ault, and JR McDonald. "Methodology for Determination of Economic Connection Capacity for Renewable Generator Connections to Distribution Networks Optimised by Active Power Flow Management." IEE Proceedings-Generation, Transmission and Distribution 153, no. 4 (2006): 456-62.

Cutler, Nicholas J, Nicholas D Boerema, Iain F MacGill, and Hugh R Outhred. "High Penetration Wind Generation Impacts on Spot Prices in the Australian National Electricity Market." Energy Policy 39, no. 10 (2011): 5939-49.

Delarue, Erik D, Patrick J Luickx, and William D D'haeseleer. "The Actual Effect of Wind Power on Overall Electricity Generation Costs and Co2 Emissions." Energy Conversion and Management 50, no. 6 (2009): 1450-56.

Doherty, Ronan, and Mark O'Malley. "Quantifying Reserve Demands Due to Increasing Wind Power Penetration." Paper presented at the 2003 IEEE Bologna Power Tech Conference Proceedings, 2003.

Energy Information Administration (EIA). 2019. Electric Power Monthly, February 2019. Washington, DC: US Energy Information Administration.

Forrest, Sam, and Iain MacGill. "Assessing the Impact of Wind Generation on Wholesale Prices and Generator Dispatch in the Australian National Electricity Market." Energy Policy 59 (2013): 120-32. 
General, Auditor. "Electricity Sector-Renewable Energy Initiatives." 2011 Annual Report of the Office of the Auditor General of Ontario 3 (2011).

Gillingham, Kenneth, and James H Stock. "The Cost of Reducing Greenhouse Gas Emissions." Journal of Economic Perspectives 32, no. 4 (2018): 53-72.

Göransson, Lisa, and Filip Johnsson. "Dispatch Modeling of a Regional Power Generation System-Integrating Wind Power." Renewable Energy 34, no. 4 (2009): 1040-49.

Graf, Christoph, and Claudio Marcantonini. "Renewable energy and its impact on thermal generation." Energy economics 66 (2017): 421-430.

Green, Richard, and Nicholas Vasilakos. "Market Behaviour with Large Amounts of Intermittent Generation." Energy Policy 38, no. 7 (2010): 3211-20.

Green, Richard, Nicholas Vasilakos, and South Kensington. "The Long-Term Impact of Wind Power on Electricity Prices and Generating Capacity." University of Birmingham Economics Discussion Paper (2011): 11-09.

Holttinen, Hannele. The Impact of Large-Scale Wind Power Production on the Nordic Electricity System. VTT Technical Research Centre of Finland, 2004.

Hoskins, E. "Charting the Costs and Effectiveness of Renewable Energy in Europe." Edmhdotme Blog (2015).

IESO. 2018. “An Adequacy Assessment of Ontario’s Electricity System.” Reliability Outlook, December 2018.

Kaffine, Daniel T, Brannin J McBee, and Jozef Lieskovsky. "Emissions Savings from Wind Power Generation in Texas." The Energy Journal 34, no. 1 (2013).

Kascor, P. 2017. "The Wolfe Island Wind Farm: An Economic Cost Benefit Case Study". MA Essay submitted to the Department of Economics, Queens University.

Kriegler, Elmar. "The status and prospects of renewable energy for combating global warming Comment." (2011): 594-596.

Lacal-Arántegui, Roberto. "2012 Jrc Wind Status Report." Available at SSRN 2541017 (2013). Joint Research Centre, Institute for Energy and Transport, European Commission, https://setis.ec.europa.eu/system/files/JRC_wind_status_report_0.pdf.

Lamont, Alan D. "Assessing the Long-Term System Value of Intermittent Electric Generation Technologies." Energy Economics 30, no. 3 (2008): 1208-31.

Ma, Tao, Hongxing Yang, Lin Lu, and Jinqing Peng. "Optimal Design of an Autonomous Solar- 
Wind-Pumped Storage Power Supply System." Applied Energy 160 (2015): 728-36.

Nicholson, E, J Rogers, and Kevin Porter. Relationship between Wind Generation and Balancing Energy Market Prices in Ercot: 2007-2009. National Renewable Energy Lab. (NREL), Golden, CO (United States) (2010).

Nicolosi, Marco. "Wind Power Integration and Power System Flexibility-an Empirical Analysis of Extreme Events in Germany under the New Negative Price Regime." Energy policy 38, no. 11 (2010): 7257-68.

Novan, Kevin. "Valuing the Wind: Renewable Energy Policies and Air Pollution Avoided." American Economic Journal: Economic Policy 7, no. 3 (2015): 291-326.

Oji, Chijioke, and Olaf Weber. "Renewable Energy Projects for Sustainable Development: Financing Options and Policy Alternatives." (2017)." Centre for International Governance Innovation Paper no. 122.

Ontario Society of Professional Engineers (OSPE). 2012. "Wind and the Electrical Grid Mitigating the Rise in Electricity Rates and Greenhouse Gas Emissions." Ontario Society of Professional Engineers.

Sensfuß, Frank, Mario Ragwitz, and Massimo Genoese. "The Merit-Order Effect: A Detailed Analysis of the Price Effect of Renewable Electricity Generation on Spot Market Prices in Germany." Energy policy 36, no. 8 (2008): 3086-94.

Sheet, EPA Fact. "Social Cost of Carbon." United States Environmental Protection Agency (EPA): Washington, DC, USA (2013).

Strbac, Goran, Anser Shakoor, Mary Black, Danny Pudjianto, and Thomas Bopp. "Impact of Wind Generation on the Operation and Development of the UK Electricity Systems." Electric power systems research 77, no. 9 (2007): 1214-27.

Ummels, BC, M Gibescu, WL Kling, and GC Paap. "Integration of Wind Power in the Liberalized Dutch Electricity Market." Wind Energy: An International Journal for Progress and Applications in Wind Power Conversion Technology 9, no. 6 (2006): 579-90.

van Kooten, G Cornelis. "The Economics of Wind Power." Annual Review of Resource Economics 8 (2016): 181-205.

Weigt, Hannes. "Germany's Wind Energy: The Potential for Fossil Capacity Replacement and Cost Saving." Applied Energy 86, no. 10 (2009): 1857-63. 
Woo, Chi-Keung, Ira Horowitz, Jack Moore, and Andres Pacheco. "The Impact of Wind Generation on the Electricity Spot-Market Price Level and Variance: The Texas Experience." Energy Policy 39, no. 7 (2011): 3939-44.

Yatchew, Adonis, and Andy Baziliauskas. "Ontario feed-in-tariff programs." Energy Policy 39, no. 7 (2011): 3885-3893.

Yauch, Brady, and S Mitchnick. "Power Exports at What Cost?". Energy Probe 9 (2016). 